\title{
Işıklı Gölü( Denizli) Makrobentik Faunasının Mevsimsel Değişimi
}

\section{Gözde AKBABA* Yunus Ömer BOYACI}

Süleyman Demirel Üniversitesi, Su Ürünleri Fakültesi, Su Ürünleri Temel Bilimler Anabilim Dalı, Isparta

*Sorumlu yazar: gosde_89@msn.com

Basılı ISSN: 1300 - 4891E. Dergi ISSN: 1308 - 7517

Özet

$\mathrm{Bu}$ çalışma, Denizli ili sınırları içinde bulunan Işıklı Gölü’nün bentik makroomurgasızlarını ve dağılımlarını belirlemek amacıyla yapılmıștır. Ișıklı Gölü üzerinde belirlenen 7 istasyonda mevsimsel periyotlarla fiziko-kimyasal açıdan incelenmiş ve bentik makroomurgasız örnekleri toplanmıştır. Çalışma sonucunda, gölün bentik faunasının ait 35 taksondan oluştuğu saptanmıştır. Makroomurgasızlar içerisinde en baskın grup Insecta sınıfı olmuştur. Mevsimlere göre taxonların dağılımı ve istasyonlar arasındaki farklılıklar gölün limnolojik yapısına bağlantılı olarak değerlendirilmiştir. Toplanan bentik makroomurgasız örnekleri tür veya cins seviyesinde teşhis edilerek bunların sıklık ve baskınlık analizleri yapılmıştır.

Anahtar kelimeler: Makrobentik Fauna, Mevsimsel

The Seasonal Change Of Macrobenthic Fauna In Işıklı Lake (Denizli)

\begin{abstract}
This study has been carried out in Işıklı Lake which is located within the city borders of Denizli, to determine the Iş1klı Lake benthic macroinvertebrates and their distributions. Water samples were taken from seven stations on Işıklı Lake seasonally an investigated about the physico-chemical characteristics. Benthic macroinvertebrates were also collected from those seven stations of Işıklı Lake.At the end of the study, benthic fauna of the lake were determined a total 35 numbers of taxa which belong to Gastrapoda, Crustacea, Oligochaeta, Hirudinea and Insecta. Insecta was found to be the most dominant group among benthic macroinvertebrates. The distribution according to the seasons of taxon and the differences between the stations was evaluated base on the lake's limnological structure The collected benthic macroinvertebrates were identified according to their species or genus levels and the frequency and dominancy done.
\end{abstract}

Key words: Işıklı Lake, Benthic Macroinvertebrates, Seasonally

Bu çalışma Süleyman Demirel Üniversitesi Bilimsel Araştırma Projeleri Koordinasyon Birimi (SDÜBAP 3903-YL1-14) tarafindan desteklenmiştir

\section{GİRIŞ}

Büyük Menderes Nehri'ni besleyen kaynakların birleşim yerinde ve Akdağ'ın Güneyinde yer alan maksimum 7 m. Derinliğindeki Işıklı Bölü, Akçay, Işıklı Kaynakları, yeraltı suyu ve Büyük Menderes'in yukarı havzadaki iki büyük kolu tarafindan beslenmektedir. Eskiden Çivril-Dinar tektonik çöküntü havzasında (Lahn, 1948; Aygen ve Balık, 2005) yağışların bol olduğu zamanlarda göl alanının genişlemesinden ve civardaki yerleşim yerleri ile tarım alanlarına zarar vermesinden dolayı 1949 yılında DSİ tarafından taşkından koruma çalışmaları başlatılmıştır. 1968 yılında da gölün batı, güney ve doğu kıyıları setle çevrilmiştir (Yarar ve Magnin, 1997). Bundan sonra göl baraj gölü niteliği kazanmıştır. Çivril gölü bugün çevredeki ovalarda yapılan büyük çaplı sulamalar için su depolanan bir rezervuar olarak kullanılmaktadır. Gölün ortasında birkaç saz adacığı 
bulunur. Gölün batı ve doğu kıyılarında geniş kavaklıklar ve tarım alanları, güneyde ise hububat ekiminin yapıldığı geniş bir ova vardır (Aygen ve Balık, 2005).

Gölün yüzey alanı çok değişkendir. Sulama amaçlı olduğu için, sulamanın yapıldığı aylar da su yüksekliği düşmekte, buna paralel olarak yüzey alanı da azalmaktadır.

Sulamanın başladığ Haziran ayından itibaren, su seviyesindeki düşüşe paralel olarak göl yüzeyinin büyük bir kısmını su içi bitkileri kaplamakta ve balık avcılığını zorlaştırmaktadır. Sucul bitkilerin nispeten daha az olduğu kısım sadece Büyük Menderes'in yatağıdır. Özellikle Temmuz, Ağustos ve Eylül aylarında göl yüzey alanının yaklaşık \%60-70'ini sucul bitkiler kaplamaktadır (Aygen ve Balık, 2005).

Limnolojik çalışmaların genel amacı, çalışılan sucul ekosistemin doğal zenginliğini ortaya koymaya yöneliktir. Bu kapsamda, iç suların doğal zenginliği şüphesiz ortamın flora ve faunasına bağlıdır.

Sucul ekosistemlerde yaşayan canlı grupların kendi aralarındaki ve içinde bulundukları ekosistemin fiziksel ve kimyasal özellikleriyle ilişkilerinin belirlenmesi çalışmaları, hem balıkçılık ve su ürünleri bakımından ekosistemden yararlanabilme sınırlarını belirlemede ve sucul ekosistemin temel biyolojik verimliliğinin belirlenebilmesi açısından gereklidir (Kirg1z, 1984).

İç sularda bentik fauna ile ilgili çalışmalar, limnolojik çalışmaların önemli bölümlerinden birini oluşturmaktadır. Bentik faunayı oluşturan gruplar, bu gruplara ait dağılımlar ve dağılıma etki eden çeşitli faktörlerin araştırılması, bu kapsamda ele alınan çalışma konularıdır. Göl ekosisteminde yaşayan bentik omurgasız organizmalar, göldeki besin zincirinin fitoplanktonik ve zooplanktonik organizmalardan sonraki üçüncü halkasını oluşturmakta ve gölün biyolojik verimliliğinde etken organizmalar olarak önem kazanmaktadir.

Bentik omurgasız organizmalar, tür kompozisyonları, biyomas değerleri, mevsimsel değişimleri ve bazı türler açısından değerlendirilerek; göllerin ekolojik yapılarının belirlenmesinde, su kalitesinin ve kirliliğinin saptanmasında önemli indikatör olarak yer almaktadır (Sözen ve Yiğit, 1999).

\section{MATERYAL ve YÖNTEM}

Çalışma toplam 7 istasyondan mevsimsel periyotlar halinde su ve bentik örnekleri alınarak yürütülmüştür (Şekil 1). Göl suyunun su sıcaklığ1 ve çözünmüş oksijen değerleri, taşınabilir WTW Oxi 320 metre ile, elektriksel iletkenlik ve tuzluluk arazi modeli YSI 30 S-C-T metre ile, pHtaşınabilir WTW Ph 330-i pH metre ile arazide ölçülmüştür.

Bentik makroomurgasız örnekleri ise, derinliği fazla istasyonlardan Ekman-Birge grab $(15 \times 15 \mathrm{~cm})$ ile toplanmıştır. Bentik organizmalar, alınan dip çamuru örneklerinin göz aralıkları farklı 2 elekten yıkanıp süzülmesiyle elde edilmiştir. Derinliğin fazla olmadığı kıyı kesimlerdeki istasyonlardan ise tabanda bulunan kaya, taş, çakı1 parçalarının altından, sucul bitkilerin arasından $500 \mu \mathrm{m}$ gözenek açıklığı olan tül geçirilmiş saplı bentik kepçesi yardımıyla elde edilmiş ve \% 70' lik alkolde fikse edilmişlerdir.

Örneklerin tür tayinleri;

Chrinomidae için, Şahin (1984,1987a,b,1991), Kırg1z (1988), Pennak (1989), Epler (1995),

Oligochaeta için, Brinkhurst (1971, 1978), Brinkhurst ve Jamieson (1971), Milligan (1997), Sperber (1948, 1950), Timm (1999) ve Wetzel ve ark.,(2000), 
Ephemeroptera için, Kimmins (1972), Roldon (1980), Belfiore (1983), Kazanc1 (1985a), Berner ve Pescador (1987), Eliot vd., (1988), Tercedor (1990), Tanatmış (1993), Haybach (1999),

Coleoptera için, Illies(1955), Brauer (1909),

Trichoptera için, Ulmer (1961), Jansson ve Vuoristo (1979), Brohmer (1979), Edington ve Hildrew (1981), Morse (1983), Wallace vd., (1990),

Odanata için, Demirsoy (1982), Stobbe (1985) ve Askew (1988),

Crustacea için, Fitzpatrick (1983),

Gastropoda için, Glöer vd., (1985),

Hirudineaiçin,Eliot ve Mann (1979),

Chaboridae için, Balvay (1977) ve Saether (1972) gibi kaynaklar kullanılarak yapılmıştır.

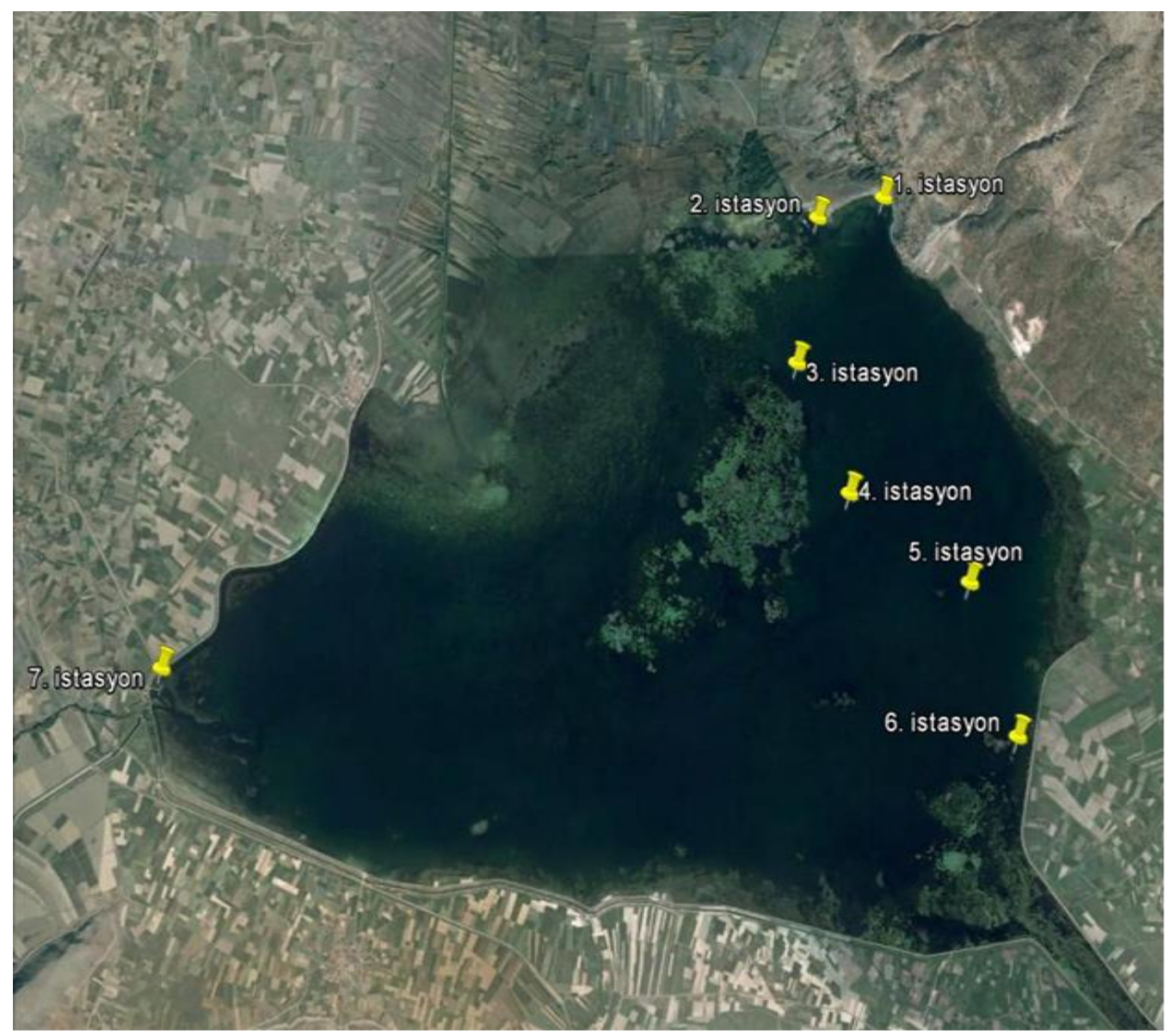

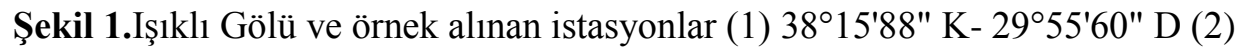

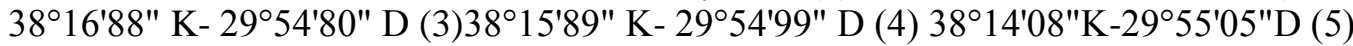
$38^{\circ} 12^{\prime} 15^{\prime \prime K}-29^{\circ} 56^{\prime} 29^{\prime \prime D}(6) 38^{\circ} 13^{\prime} 60^{\prime \prime K}-29^{\circ} 57^{\prime} 16^{\prime \prime} \mathrm{D}$ (7)38 $19^{\circ} 44^{\prime \prime K}-29^{\circ} 51^{\prime} 08^{\prime \prime}$ 


\section{BULGULAR}

Fiziksel ve Kimyasal Bulgular

Tablo 1. İstasyonlarda farklı mevsimlerde saptanan su kalitesi değerleri

\begin{tabular}{|c|c|c|c|c|c|c|c|c|}
\hline \multirow{2}{*}{$\begin{array}{l}\text { Su Kalitesi } \\
\text { Değerleri }\end{array}$} & \multicolumn{8}{|c|}{ İSTASYONLAR } \\
\hline & 1.ist. & 2.ist. & 3.ist. & 4.ist & 5.ist & 6.ist & 7.ist. & $\operatorname{Ort} \pm \mathbf{S E}$ \\
\hline Sicaklık $\left({ }^{\circ} \mathrm{C}\right)$ & 21,6 & 22,5 & $21^{\circ} \mathrm{C}$ & 20,2 & 20,5 & 24 & 14,7 & $20,6 \pm 2,71$ \\
\hline $\begin{array}{l}\text { Çözünmüş } \\
\text { O}_{2} \text { (mg/ltt) }\end{array}$ & 9 & 6,5 & 11,4 & 9.4 & 8,8 & 9,26 & 6 & $8,62 \pm 1,39$ \\
\hline pH & 10 & 9,36 & 9,46 & 9,4 & 9,32 & 9,26 & 8,94 & $9,39 \pm 0,32$ \\
\hline El. İlet. $\left(\mu \mathrm{S} \mathbf{c m}^{-1}\right)$ & 257,8 & 392,7 & 293 & 302,3 & 370 & 391 & 762 & $396 \pm 157,3$ \\
\hline Sicaklık $\left({ }^{\circ} \mathrm{C}\right)$ & 21,5 & - & 22,6 & 25,2 & 21,6 & 26,8 & 15,4 & $22,18 \pm 3,6$ \\
\hline $\begin{array}{l}\text { Çözünm } \\
\text { O}_{2}(\mathrm{mg} / \mathrm{l}\end{array}$ & 6,95 & - & 7,09 & 7,35 & 6,73 & 6,25 & 6,4 & $6,79 \pm 0,42$ \\
\hline pH & 9,9 & - & 10,2 & 7,33 & 9,40 & 9,7 & 9,42 & $9,32 \pm 1,02$ \\
\hline El. İlet. $\left(\mu \mathrm{S} \mathrm{cm}^{-1}\right)$ & 380 & - & 528 & 318 & 421 & 403,5 & 605 & $443 \pm 104,9$ \\
\hline Sicaklık $\left({ }^{\circ} \mathrm{C}\right)$ & 13,1 & 14 & 14,8 & 14,2 & 14,8 & 15 & 16 & $14,5 \pm 0,908$ \\
\hline $\begin{array}{l}\text { Çözünmüuş } \\
\text { O}_{2} \text { (mg/ltt) }\end{array}$ & 7,53 & 8,3 & 11 & 9,6 & 7,6 & 9,2 & 6,7 & $8,6 \pm 1,36$ \\
\hline pH & 8,11 & 8,26 & 8,06 & 7,27 & 7,94 & 8,03 & 7,44 & $7,9 \pm 0,36$ \\
\hline El. İlet. $\left(\mu \mathrm{S} \mathrm{cm}^{-1}\right)$ & 254 & 337 & 364 & 296 & 388 & 438 & 586 & $380,5 \pm 107,63$ \\
\hline Sicaklık $\left({ }^{\circ} \mathrm{C}\right)$ & 2,6 & 4,5 & 4,7 & 2,5 & 4,5 & 4,7 & 14 & $5,35 \pm 3,93$ \\
\hline $\begin{array}{l}\text { Çözünmüş } \\
\text { O}_{2} \text { (mg/lt) }\end{array}$ & 7,1 & 7,6 & 11,7 & 8,6 & 8,5 & 8,4 & 6,85 & $8,39 \pm 1,62$ \\
\hline pH & 8,01 & 8,32 & 8,55 & 7,3 & 7,43 & 7,4 & 7,9 & $7,84 \pm 0,486$ \\
\hline El. İlet. $\left(\mu \mathrm{S} \mathrm{cm}^{-1}\right)$ & 270 & 350 & 276 & 317 & 371 & 328 & 600 & $358,9 \pm 104,08$ \\
\hline
\end{tabular}

\section{Biyolojik Bulgular}

Çalışma sonunda Işıklı Gölü’nde Crustacea sınıfına ait 1 cins 3 tür düzeyinde 4 takson, Gastropoda sınıfına ait tür düzeyinde 9 takson, Hirudinea sınıfına ait tür düzeyinde 1 takson, Oligochaeta sınıfına ait 5 takson ve Insecta sinıfina ait 4 cins 12 tür düzeyinde 16 takson, toplam 35 takson teşhis edilmiştir. Türlerin örnekleme noktalarına göre dağılımları Çizelge 2'de verilmiştir. 
Tablo 2.Işıklı Gölü’nde teşhis edilen taksonlar ve istasyonlara göre dağılımları

\begin{tabular}{|c|c|c|c|c|c|c|c|}
\hline \multirow{2}{*}{ TAKSONLAR } & \multicolumn{7}{|c|}{ İSTASYONLAR } \\
\hline & 1 & 2 & 3 & 4 & 5 & 6 & 7 \\
\hline \multicolumn{8}{|l|}{ GASTROPODA } \\
\hline Planorbis planorbis $(\mathrm{L} ., 1758)$ & $\mathbf{x}$ & $\mathbf{x}$ & $\mathbf{x}$ & $\mathbf{x}$ & $\mathbf{x}$ & $\mathbf{x}$ & \\
\hline Planorbis carinatus(M.,1774) & $\mathbf{x}$ & & & & $\mathbf{x}$ & & \\
\hline Planorbis corneus (L.,1758) & & & $\mathbf{x}$ & & $\mathbf{x}$ & & \\
\hline Physa fontinalis (L.,1758) & $\mathbf{x}$ & & & $\mathbf{x}$ & & $\mathbf{x}$ & \\
\hline Radix ovata (Draparnaud, 1805) & $\mathbf{x}$ & & $\mathbf{x}$ & & $\mathbf{x}$ & $\mathbf{x}$ & \\
\hline Lymnea stegnalis(L.,1758) & $\mathbf{x}$ & & $\mathbf{x}$ & $\mathbf{x}$ & $\mathbf{x}$ & & \\
\hline Radix peregra(M.,1774) & & & & $\mathbf{x}$ & $\mathbf{x}$ & & \\
\hline Valvata pulchella & $\mathbf{x}$ & $\mathbf{x}$ & $\mathbf{x}$ & $\mathbf{x}$ & & & \\
\hline Viviparus viviparus(L.,1758) & $\mathbf{x}$ & & & & & $\mathbf{x}$ & \\
\hline \multicolumn{8}{|l|}{ OLIGOCHAETA } \\
\hline Tubifex tubifex (Müller, 1774) & & & $\mathbf{x}$ & $\mathbf{x}$ & $\mathbf{x}$ & & \\
\hline Limnodrilus hoffmeistri (Claparéde, 1862) & & & $\mathbf{x}$ & $\mathbf{x}$ & & & \\
\hline Limnodrilus udekemianus (Claparéde,1862) & & & & & $\mathbf{x}$ & & \\
\hline $\begin{array}{l}\text { Potamothrix hammoniensis (Michaelsen, } \\
\text { 1901) }\end{array}$ & & & $\mathbf{x}$ & $\mathbf{x}$ & $\mathbf{x}$ & & \\
\hline Stylaria lacustris( L.,1767) & & & & & $\mathbf{x}$ & & \\
\hline \multicolumn{8}{|l|}{ HIRUDINEA } \\
\hline Hirudo medicinalis (L.,1758) & $\mathbf{x}$ & & & & & & \\
\hline \multicolumn{8}{|l|}{ CRUSTACEA } \\
\hline $\begin{array}{l}\text { Gammarus obnixus (Karaman \& Pinkster, } \\
\text { 1977) }\end{array}$ & $\mathbf{x}$ & $\mathbf{x}$ & & & & & \\
\hline Gammarus balcanicus (Schaferna, 1922) & & & & & & & $\mathbf{x}$ \\
\hline Paramysis kosswigi (Bacescu, 1948 ) & $\mathbf{x}$ & $\mathbf{x}$ & & $\mathbf{x}$ & & & $\mathbf{x}$ \\
\hline \multicolumn{8}{|l|}{ INSECTA } \\
\hline$\overline{\text { Disticus verticalis (L., 1758) }}$ & $\mathbf{x}$ & $\mathbf{x}$ & & & & $\mathbf{x}$ & \\
\hline Íchnura elegans (Van der Linden, 1820) & $\mathbf{x}$ & $\mathbf{x}$ & & & & $\mathbf{x}$ & \\
\hline Libellula sp & $\mathbf{x}$ & $\mathbf{x}$ & & & & $\mathbf{x}$ & \\
\hline Aeshna sp. & $\mathbf{x}$ & $\mathbf{x}$ & & & & & \\
\hline Corixa punctata (Illiger, 1807) & $\mathbf{x}$ & $\mathbf{x}$ & $\mathbf{x}$ & & $\mathbf{x}$ & $\mathbf{x}$ & \\
\hline Sigara lateralis (Leach, 1817) & $\mathbf{x}$ & $\mathbf{x}$ & $\mathbf{x}$ & & $\mathbf{x}$ & $\mathbf{x}$ & \\
\hline Baetis scambus (Eaton, 1870) & $\mathbf{x}$ & $\mathbf{x}$ & & & & & \\
\hline Baetis rhodani (Pictet, 1843) & $\mathbf{x}$ & $\mathbf{x}$ & & & & & \\
\hline Chironomus plumosus (Linnaeus, 1758) & $\mathbf{x}$ & & $\mathbf{x}$ & & $\mathbf{x}$ & & \\
\hline Chironomus tentans (Linnaeus, 1758) & $\mathbf{x}$ & $\mathbf{x}$ & $\mathbf{x}$ & & $\mathbf{x}$ & $\mathbf{x}$ & \\
\hline Polypedilum lateum (Meigen, 1818) & $\mathbf{x}$ & & & & & & \\
\hline Pentapedilum exsectum (Kieffer, 1916) & $\mathbf{x}$ & & $\mathbf{x}$ & $\mathbf{x}$ & & $\mathbf{x}$ & \\
\hline Tanypus kraatzi (Kieffer, 1912) & & & $\mathbf{x}$ & & $\mathbf{x}$ & & \\
\hline Chaborus crystallinus(De Geer, 1776) & $\mathbf{x}$ & $\mathbf{x}$ & & & & & \\
\hline Hydroptila sp. & $\mathbf{x}$ & $\mathbf{x}$ & & & & & \\
\hline Lepidostoma sp. & $\mathbf{x}$ & $\mathbf{x}$ & & & & & \\
\hline TOPLAM & 2055 & 1091 & 1391 & 1203 & 1606 & 858 & 1825 \\
\hline
\end{tabular}




\section{Örnekleme noktalarında bentik makroomurgasız taksonlarının baskınlığı}

Arazi çalışması boyunca, Işıklı Gölü'ndeki her bir istasyonda bulunan türlerin baskınlık değerleri hesaplanmış ve bu değerler Çizelge 3' de verilmiştir.

Tablo 3. Örnekleme noktalarındaki taksonların baskınlık değerleri

\begin{tabular}{|c|c|c|c|c|c|c|c|c|}
\hline & \multirow{2}{*}{ TAKSONLAR } & \multicolumn{7}{|c|}{ İSTASYONLARDAKİ BASKINLIK DEĞERLERİ (\%) } \\
\hline & & 1.ist & 2.ist & 3.ist & 4.ist & 5.ist & 6.ist & 7.ist \\
\hline \multirow{10}{*}{ 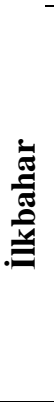 } & Pentapedilum exsectum & 10,64 & & & & & & \\
\hline & Gammarus obnixus & 10,10 & 14,41 & & & & & \\
\hline & Corixa punctata & 9,56 & 12,38 & & & & 17,12 & \\
\hline & Aeshna sp. & & 12,38 & & & & & \\
\hline & Limnodrilus hoffmeistri & & & 29,76 & 36,41 & & & \\
\hline & Tubifex tubifex & & & 28,57 & 21,53 & 18,57 & & \\
\hline & Limnodrilus udekemianus & & & & & 36,04 & & \\
\hline & Planorbis planorbis & & & & & & 24,21 & \\
\hline & Gammarus balcanicus & & & & & & & 86,12 \\
\hline & Paramysis kosswigi & & & & & & & 13,06 \\
\hline \multirow{10}{*}{$\underset{ }{~ స ్}$} & Gammarus obnixus & 14,7 & & & & & & \\
\hline & Paramysis kosswigi & 12,11 & & & 21,6 & & & \\
\hline & Potamothrix hammoniensis & & & 29,9 & 43,26 & & & \\
\hline & Chironomus plumosus & & & 12,35 & & & & \\
\hline & Limnodrilus udekemianus & & & & & 26,89 & & \\
\hline & Potamothrix hammoniensis & & & & & 17,01 & & \\
\hline & Physa fontinalis & & & & & & 20,08 & \\
\hline & Corixa punchtata & & & & & & 15,16 & \\
\hline & Gammarus balcanicus & & & & & & & 78,98 \\
\hline & Paramysis kosswigi & & & & & & & 20,28 \\
\hline \multirow{11}{*}{ 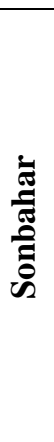 } & Planorbis planorbis & 16,92 & & & & & & \\
\hline & Planorbis carinatus & 14,56 & & & & & & \\
\hline & Sigara lateralis & & 22,68 & & & & & \\
\hline & Valvata pulchella & & 20,83 & & & & & \\
\hline & Chaborus crystallinus & & 20,37 & & & & & \\
\hline & Tubifex tubifex & & & 24,56 & 23,36 & 19,02 & & \\
\hline & Limnodrilus hoffmeistri & & & 22,24 & 35,98 & & & \\
\hline & Limnodrilus udekemianus & & & & & 29,93 & & \\
\hline & Corixa punchtata & & & & & & 25,13 & \\
\hline & Planorbis planorbis & & & & & & 24,02 & \\
\hline & Gammarus balcanicus & & & & & & & 100 \\
\hline \multirow{9}{*}{$\underline{2}$} & Hydroptila sp. & 23,5 & 29,04 & & & & & \\
\hline & Lepidostoma sp. & 13,21 & 31,13 & & & & & \\
\hline & Tanypus kraatzi & & & 78,28 & & & & \\
\hline & Tubifex tubifex & & & & 76,42 & 35,38 & & \\
\hline & Lymnea stegnalis & & & & 23,57 & & & \\
\hline & Corixa punchtata & & & & & & 56,06 & \\
\hline & Sigara lateralis & & & & & & 36,6 & \\
\hline & Gammarus balcanicus & & & & & & & 88,08 \\
\hline & Paramysis kosswigi & & & & & & & 11,92 \\
\hline
\end{tabular}




\section{Bentik makroomurgasızların örnekleme noktalarına göre sıklık değerleri}

Sıklık analiz formülü $(\operatorname{Siklık}(\mathrm{F})=(\mathrm{Na} / \mathrm{Nn}) \times 100)$ uygulanarak $(\mathbf{N a}=\mathrm{A}$ türünü içeren örnekleme sayısı, $\mathbf{N n}=$ Tüm örnekleme sayısı) bentik makroomurgasızların örnekleme noktalarına göre sıklık değerleri belirlenmiş ve sıklık kategorilerine göre sınıflandırılmıştır (Kocataş, 1994).

I. istasyonda, Planorbis planorbis, Corixa punchtata, Sigara lateralis, Pentapedilum exsectum devamlı bulunan taksonlardır. Planorbis carinatus, Lymnea stegnalis, Paramysis kosswigi, Aeshna sp., çoğunlukla bulunan taksonlardır. Physa fontinalis, Radix ovata, Valvata pulchella, Viviparus viviparus, Hirudo medicialis, Gammarus obnixus, Disticus verticalis, Ichnura elegans, Libellula sp., Chironomus tentans, Chaborus crystallinus genellikle bulunan taksonlardır. Baetis scambus, Baetis Rhodani, Chironomus plumosus, Polypedilum lateum, Hidroptila sp.,Lepidostoma sp. seyrek bulunan taksonlardır.

II. istasyonda, Planorbis Planorbis, Corixa punchtata, Sigara lateralis çoğunlukla bulunan taksonlardır. Chaborus crystallinus genellikle bulunan taksondur. Valvata pulchella, Gammarus obnixus, Paramysis kosswigi, Disticus verticalis, Ichnura elegans, Libellula sp.,Aeshna sp., Baetis scambus, Baetis Rhodani, Chironomus tentans, Hidroptila $s p .$, Lepidostoma $s p$. seyrek bulunan taksonlardır.

III. istasyonda, Planorbis planorbis, Planorbis corneus, Lymnea stegnalis, Pentapedilum exsectum, Tanypus kraatzi çoğunlukla bulunan taksondur. Radix ovata, Valvata pulchella, Tubifex tubifex, Limnodrilus hoffmeistri, Potamothrix hammoniensis, Sigara lateralis, Chironomus tentans genellikle bulunan taksonlardır. Corixa punchtata, Chironomus plumosusseyrek bulunan taksonlardır.

IV. istasyonda, Lymnea stegnalis, Tubifex tubifex, Pentapedilum exsectum çoğunlukla bulunan taksondur. Planorbis Planorbis, Physa fontinalis, Limnodrilus hoffmeistri, Potamothrix hammoniensis genellikle bulunan taksonlardır. Radix peregra,Valvata pulchella, Paramysis kosswigi seyrek bulunan taksonlardır.

V. istasyonda, Planorbis corneus devaml1 bulunan taksondur. Planorbis planorbis, Lymnea stegnalis, Tubifex tubifex, Limnodrilus udekemianus, Corixa punchtata, Sigara lateralis, Tanypus kraatzi çoğunlukla bulunan taksonlardır. Planorbis carinatus, Potamothrix hammoniensis genellikle bulunan taksonlardır. Radix ovata, Radix peregra, Stylaria lacustris, Chironomus plumosus, Chironomus tentans seyrek bulunan taksonlardır.

VI. istasyonda, , Corixa punchtata, Sigara lateralis devamlı bulunan taksonlardir. . Planorbis Planorbis, Radix ovata, Viviparus viviparus, Disticus verticalis, Ichnura elegans, Libellula sp. genellikle bulunan taksonlardır. Physa fontinalis, Chironomus tentans seyrek bulunan taksondur.

VII. istasyonda, Gammarus balcanicus devaml1 bulunan taksondur. Paramysis kosswigi çoğunlukla bulunan taksondur. Potamon sp. seyrek bulunan taksondur.

\section{TARTIŞMA ve SONUÇ}

Çivril Gölü’nün makrozoobentik faunası ve mevsimsel değişimini belirleyebilmek için mevsimsel olarak yapılan bu çalışma sonucu; Işıklı Gölü bentik faunasını Gastropoda, Oligochaeta, Hirudinea, Crustacea, Insecta siniflarına ait toplam 35 takson ve bu taksonlara ait toplam 10029 birey belirlenmiştir. Makro omurgasızlar içerisinde en fazla bireyle temsil edilen grup Insecta olmuştur. 
Yapılan örneklemelerde Annelida filumuna ait iki farklı sınıf tespit edilmiştir. Hirudinea sınıfina ait bireyler göllerde, göletlerde ve yavaş akan sularda yaygın olarak bulanabilir ve bentik komunitenin önemli birleşenlerindendir, küçük gölcüklerde genellikle besin zincirinin üst basamak avcısı olarak kabul edilmektedir (Davies 1991). Oligochaeta sınıfı üyelerine ise daimi sularda daha sık rastlanır ancak geçici sularında fauna listesinde sıklıkla yer alır (Williams, 2006). Brinkhurst ve Gelder (1991) Oligochaeta türlerinin alan seçimlerinin sediment yapısının özellikleri ile ilişkili olduğunu, özellikle organik birleşenlerin bol olduğu sedimentlerde bulunma eğilimlerinin olduğunu belirtmişlerdir. Gerçekleştirilen bu çalışmada Oligochaeta bölümündenTubifex tubifex, Limnodrilus hoffmeistri, Limnodrilus udekemianus, Potamothrix hammoniensis, Stylaria lacustris taksonları tespit edilmiştir. Limnodrilus hoffmeisteri biyolojik olarak organik kirliliğin ve ötrofik şartların indikatörü olarak bilinmektedir (Timm, 1970). Tubifex tubifex de aynı özelliklere sahiptir ve birlikte aynı ortamlarda daha sık bulunduğu bildirilmiştir (Brinhurst,1969).

Mollusca genelde organik kirliliğe karşı töleranslı olarak belirtilmiştir (Mason,1983). Gastropoda çoğu habitatlara yüksek adaptasyon kabiliyetleri ile yayılabildikleri, ekolojik olarak karasal ve sucul ekosistemlerin önemli bir parçası oldukları bildirilmektedir (Zhadin, 1952). Ayrıca gastropodların sucul ekosistemlerde kirlilik ve verimliliğin biyoindikatörü olarak kullanılabildiği belirtilmiştir (Hart et al, 1974). Bu bölüme ait9 farklı takson Planorbis planorbis, P. carinatus, P. corneus, Physa fontinalis, Radix ovata, Radix peregra, Lymnea stegnalis, Valvata pulchella, Viviparus viviparus türleri tespit edilmiştir. Türlerin dağılımı; yayılış alanları ile uygunluk göstermektedir. Vejetasyonun ve organik maddelerin varlığı, yumurtaların ve yavruların gelişimine imkân verdiğinden Planorbidae varlığını etkileyen bir parametredir. Çalışmamız sırasında daPlanorbidae üyelerinin köklü bitkilerin var olduğu sığ sularda yayılış gösterdikleri saptanmıştır (Baker 1945).

Crustacea şubesine ait 3 takım (Amphipoda, Mysidacea, Decapoda) tespit edilmiştir. Amphipoda takımından Gammarus obnixus ve Gammarus balcanicus, Mysidacea takımından Paramysis kosswigi, Decapoda takımından Potamon sp. taksonları tespit edilmiştir. Potamon sp. ve Gammarus balcanicus' ye sadece 7. istasyonda rastlanılmıştır.

Sucul böcekler geçici sulak alanlardaki ana gruplar olarak ele alınmaktadır (Williams 2006).

Hemiptera takımı Corixidae familyasına ait Corixa punchtata ve Sigara lateralis olmak üzere iki takson tespit edilmiştir. Tespit edilen bireyler genellikle göl kıyı şeridi ve göl ile bağlantılı alanlarda bulunmuştur. Bu alanlar aynı zamanda avcı türlerin yokluğu ile Corixidae için uygun alanlar olmuştur. Tully ve ark. (2004) Corixidae üyelerinin yoğun vejetasyon ve çamur substratlı alanlarda yüksek tür çeşitliliği ile mevcut olduklarını belirtmiştir En yüksek sayıda örneklemeler ilk iki örnekleme tarihinde gerçekleşmiştir ve bu bireylerin büyük çoğunluğu oldukça küçük boyutlu Corixidae nimfleridir. Corixidae yılda iklime bağlı olarak bir ya da iki nesil meydana getirir. Bazı türlerin kışı yumurta ya da nimf olarak geçirdikleri kayıt edilmiştir (Applegate ve ark. 1977).

Coleoptera takımına ait Disticus verticalis türü genellikle vejetasyonun bol, su içi bitkilerinin yoğun olduğu yerlerde ve larval formda tespit edilmiştir. Coleoptera ve Hemiptera erginleri, uçma yetenekleri ile geçici suları kuruma döneminin öncesinde terk ederek daimi suları kullanmaktadırlar (Williams, 2006). Bu sebeple kirlenmenin son noktasında su ortamını en son terk eden canlılar arasındadırlar. 
Odonata takımına ait 3 takson (Ichnuraelegans.,Libellula sp., Anax sp.) bulunmuştur. Genellikle sazlıkların, bitki vejetasyonlarının çok olduğu bölgelerde yayılmışlardır. Örnekleme yaptı̆̆ımız Mayıs ve Ağustos aylarında Odonataya ait larval örneklere rastlanılmıştır fakat Kasım ve Şubat aylarında örnek bulunamamıştır.

Ephemeroptera takımına ait 2 takson (Baetis scambus ve Baetis rhodani) bulunmuştur. Ephemeroptera nimfleri sulardaki besin zincirinin önemli bir halkasını oluşturdukları için, tür çeşitlilikleri ve bollukları suların biyolojik verimliliğinin saptanmasında doğru sonuçlar verirler. Örnekleme yaptı̆̆ımız Mayıs ayında Ephemeropteraya ait larval örneklere rastlanılmıştır.

Trichopteralar hemen hemen her habitata yayılmışlardır. Trichoptera larvaları tatlı su habitatlarında genellikle bol ve yaygın olmaları sebebiyle sucul sistemler için önemli elemanlardır (Wiggins and Mackay, 1978). Trichopterler balıklar için önemli besin kaynağ1 oluştururmaları ve organik madde teşkil etmeleri sebebiyle sucul ekosistemde önemlidirler (Bouchard, 2004). Tricoptera takımına ait 2 takson (Hidroptia sp.ve Lepidostoma sp.) tespit edilmiştir. Su kalitesini belirlemede Ephemeropteralar ile birlikte genellikle olumlu yönde kullanılırlar.

Gölde Insecta grubu içinde en fazla birey sayısına sahip grup Diptera'dır. Diptera takımına ait iki familya tespit edilmiştir. Chaboridae familyasına ait Chaboris Cristallinus sadece I. Ve II. istasyonlarda karşımıza çıkmıştır. Chrinomidae familyasına ait Chironomus sp. türü çalışma süresince en fazla bulunan zoobentik grubudur. Chironomid larvalarından Chironomus plumosus, Chironomus tentans, Polypedilum lateum, Pentapedilum exsectum, Tanypus kraatzi taksonları tespit edilmiştir. 7. istasyon dışında tüm istasyonlarda bulunmuştur. Tüm örnekleme yapılan aylarda bulunması, yayılış alanının çok geniş olması bu grubun ekolojik toleransının oldukça yüksek olduğunu göstermektedir. Chironomus cinsine ait türler genellikle ötrof göllerde bulunmaktadır (Ayık, 2006). Bu grup kirlilik araştırmalarında kullanılan biyolojik yöntemlerde yararlanılan bir gruptur. Chironomidae familyası üyelerinin yoğunluklarının diğer böceklerin yoğunluklarına oranı ağır metal kirliliğin indikatörü olarak kullanılabileceği de varsayılmaktadır (Kazancı ve Diğg, 1997). Diptera ve Annelida takımlarının gölde çok sayıda bulunması gölün kirlilik oranının da fazla olduğunu düşündürmektedir.

Gölün maksimum derinliği Ağustos örneklememizde 4. istasyonda $520 \mathrm{~cm}$ olarak ölçülmütür. Göldeki su miktarı yıllık yağış rejimine göre değişmekle birlikte Haziran ayından itibaren gölden sulama amaçlı su çekilmesi sebebiyle de değişmekte olduğu anlaşılmaktadır. Su seviyesindeki değişimler canlıları olumsuz etkileyen önemli faktörler arasında yer alır. Ancak bu konu ile ilgili yapılan çalışmalar çok sınırlıdır. Birçok canlının bulunduğu sucul ortamlarda kıyıdan tabana kadar olan kesimlerde yer alan bentik canlılar böyle değişken olan çevre şartlarına uyum sağlamak zorundadır. Uyum işlemi birey kayıpları ile sonuçlandığı ve hatta ortamdan canlının yok olduğu gözlenmiştir.

Çalışma dönemlerinde, Işıklı Gölü'nde en düşük su sıcaklığı Şubat ayında 4. istasyonda $2,5^{\circ} \mathrm{C}$, maksimum su sicaklığ Ağustos 2014 'de 6 . istasyonda $26,8{ }^{\circ} \mathrm{C}$ olarak ölçülmüştür. Göl çok sığ olduğundan yüzey ile dip arasında herhangi bir sıcaklık farklılığ belirlenmemiştir. Işıklı Kaynağı ise yer altı suyu olması sebebiyle yıl boyunca değişmeyen sicaklık rejimine sahiptir.

Sudaki çözünmüş oksijen miktarına bakıldığında; Işıklı Gölü'nün oksijen bakımından hayli zengin olduğunu söyleyebiliriz. Çalışma süresince en düşük çözünmüş oksijen miktarı Ağustos 2014' de 6. istasyonda 6,25 mg/lt, en yüksek çözünmüş oksijen miktarı 
ise Şubat 2015 'de 3. istasyonda $11,7 \mathrm{mg} / \mathrm{lt}$ olarak ölçülmüştür. Işıklı Kaynağında tespit edilen çözünmüş oksijen değerleri ise kaynak suyunun özelliğine uygun olarak hemen hemen aynı değerde kaldığ1 saptanmıştır (max. 6,85 mg/lt / min. $6 \mathrm{mg} / \mathrm{lt}$ ). Tarımsal sulamanın başladığı aylardan itibaren, su seviyesindeki düşüşe paralel olarak göl yüzeyinin büyük bir kısmını su içi bitkileri kaplamaktadır (Aygen ve Balık, 2005). Bu durum özellikle yaz aylarında organik madde yükünün yüksek, çözünmüş oksijen miktarının ise düşük çıkmasının nedenini açıklamaktadır.

Işıklı Gölü'nde pH değerlerinin 7,27 ile 10,2 arasında değişim gösterdiği, buna göre Işıklı Gölü'nün hafif alkali karakterli olduğunu söyleyebiliriz.

Iş1klı Gölü’ nün yüzey sularında elektrik iletkenliği en düşük Kasım 2014' de 1. istasyonda $254 \mu \mathrm{S} \mathrm{cm}$, en yüksek May1s 2014' de kaynak bölgesinde bulunan 7 . istasyonda $762 \mu \mathrm{S} \mathrm{cm}^{-1}$ ölçülmüştür.

Sulama amaçlı kullanılan sular yaz aylarında çok fazla çekilmektedir. Bu durum toleransı düşük canlıların ortamdan uzaklaşmasına tür çeşitliliğinin azalmasına sebep olmaktadır. Çivril Gölü'nü kirleten en önemli kaynak, Büyük Menderes Nehri’nden gelen kirliliktir. Bunun yanında evsel kullanımlar ve tarımsal uygulamalardan dolayı olumsuz etkilerin daha az olduğu düşünülmektedir.

\section{KAYNAKLAR}

Applegate, R.L., R.W. Kieckhefer.1977. Ecology of Corixidae (Water Botman) in Lake Poinsett, South Dakota. The American Midland Naturalist, 97(1): 198 - 208.

Askew, R. R., 1988. The Dragonflies of Europea, Harley Books, 291p. Colchester- England.

Aygen, C., Balık, S. (2005). Işıklı Gölü ve Kaynaklarının (Çivril-Denizli) Crustacea Faunası. Ege Üniversitesi Su Ürünleri Dergisi 22(3-4): 371-375.

Ayık, Ö., 2006. Uluabat (Apolyont) Gölü Chironomidae (Dıptera) Limnofaunası, Yüksek Lisans tezi, Osmangazi Üniversitesi Fen Bilimleri Enstitüsü, Biyoloji A.B.D., Eskişehir

Baker, F.C. 1945. The Molluscan Family Planorbidae. The University of Illinois, Urbana, 530.

Balvay, G., 1977, Determination des larves de Chaborus (Diptera, Chaoboridae)., Rencontrees en France, Ann Hydrobiol 8(I): 27-32.

Belfiore, C., 1983. Efemerottori, Promozione Della Qualita Dell'Ambiante, AQ/ 1 /201, 119 p, Italy.

Berner, L., Pescador, L. M., 1987. The Mayflies of Florida, University Press of Florida, 217 p, Florida.

Bouchard, Jr, R.W., 2004, Guide to Awuatic Invertebrates of the Upper Midwest, University of Minnesota, 207p

Brauer, A., 1909. Die Süsswasserfauna Deutschland (Coleoptera). Verlag von Gustav Fischer Jena, 235 p. Berlin.

Brınkhurst, R.O., 1969, The Fauna of pollution.-In: D.V. ANDERSON (ed.), The Great Lakes as an Environment, Lake Institute University of Toronto, Toronto: 97-115

Brınkhurst, R. O., JAMIESON B. G. M., 1971, Aquatic Oligochaeta of the world, Oliver and Boyd, Edinburg, $860 \mathrm{p}$.

Brınkhurst, R. O.,1978, Limnofauna Europaea, Illies J., Gustav Fischer Verlag, Stuttgart, 139-147p

Brınkhurst, R.O., Gelder S.R.. 1991. Annelida: Oligochaete and Branchipodellida. In Ecology and Classification of North American FreshwaterInvertabrates. (Ed. J.H. THORP and A.P. COVICH), Academic Press, New York. 401-435

Brohmer, P., 1979. Fauna von Deutschland, 581 p, Heidelberg.

Davies, R.W. 1991. Annelida: leeches, polychaetes and acanthobdellids. In Ecology and Classification of North American Freshwater Invertabrates. (Ed. J.H. THORP and A.P. COVICH),Academic Press, New York. 437-479. 
Demirsoy, A., 1982. Türkiye Faunası (Odonata). Türkiye Bilimsel ve Teknik Araştırma Kurumu (TÜBİTAK), TBAG Seri No:28, Tübitak yayınları (508): 154s. Ankara.

Edington, J. M., Hidrew, A. G., 1981. Caseless Caddis Larvae of the British Isles. 92 p. London.

Ellot, J. M., Mann, K.H., 1979. A Key To British Freshwater Leeches, with Notes On Their Life Cycles and Ecology, Freshwater Biological Association Scientific Publication (40) 72 p. London.

Epler, J. H. 1995. Identification Manual for the Larvae Chironomidae (Diptera) of Florida. Department of Environmental Protection. Division of water facilities, Tallahassee, 308 p.

Fitzpatrick, J., 1983, Freshwater Crustacea, USA, 220p.

Glöer, P., Brook, C. M., Ostermann, O., 1985. Süsswassermollusken, ein Bestimmungsschlüssel Für die Bundesrepublik Deuschland, 81 p. Hamburg.

Hart, C.W., Samuel, L.H.F., 1974, Pollution Ecology of Freswater Invertebrates. Academic Press. Inc., New York, 389p.

Illies, J., 1955. Die Tierwelt Deutschlands Plecoptera, 150 p. Germany.

Jansson, A., Vuoristo, T., 1979. Significance of Stridulation in Larval Hydropsychidae (Trichoptera) Anim. Behav., 71: 168-186.

Kazanc1 N., 1985. Gümüşhane, Erzurum, Erzincan, Artvin, Kars illerinde Ephemeroptera (insecta) Takımı Nimflerin ve Erginlerin Sistematik Yönden İncelenmesi. Hacettepe Üniversitesi, Fen Bilimleri Enstitüsü, Doktora Tezi, $80 \mathrm{~s}$, Ankara.

Kazanc1, N., Girgin, S., Dügel, M., Oğuzkurt, D., 1997, Türkiye İç Suları Araştırmaları Dizisi: II., Akarsuların Çevre Kalitesi Yönünden Değerlendirilmesinde ve İzlenmesinde Biyotik İndeks Yöntemi, Form Ofset, 100 s., Ankara. ISBN 975-7852-38-4.

Kırgız, T., 1984. Seyhan Baraj Gölü Bentik Hayvansal Organizmaları ve Bunların Nitel ve Nicel Dağılımları, Ç.Ü.Fen Bil. Enst. Biyoloji ABD Doktora Tezi, Adana.

Kırgız, T., 1988a. Seyhan Baraj Gölü Bentik Hayvansal Organizmaları ve Bunların Nitel ve Nicel Dağlımları, Doğa TU. Zooloji Derg. 12(3)231-245s.

Kırgız, T., 1988b. Gala Gölü Chironomidae (Diptera) Larvaları Üzerinde Bir Ön Araştırma, IX. Ulusal Biyoloji Kongresi, 21-23 Eylül 1988, Cilt (2) 489- 498,Sivas.

Kimmins, D. E., 1972. A Revised Key to the Adults of The British Species of Ephemeroptera with Notes on Their Ecology, 76 p. Westmorland.

Lahn, E., 1948, Türkiye Göllerinin Jeolojisi Ve Jeomorfolojisi Hakkında bir Etüd. Maden Tetkik ve Arama Enstitüsü Yayınlarından, Seri B, No:12,87 s.

Mason, C.E., 1983, Biology of Freswater Pollution, Longman House, London.

Milligan, M.R., 1997, Identification Manual for The Aquatic Oligochaeta of Florida, Vol:I, Freshwater Oligochaetes, State of Florida Department of Environmental Protection Tallahassee, Florida, 175 p.

Morse, J. C., 1983. Proceedings of the Fourth International Symposium on Trichoptera. Junk Publishers, 486 p. South Carolina.

Pennak, R. W., (1991). Fresh Water Invertebrates of United States Boulder, Colarado, 295-296.

Roldon, G., 1980. Limnological Studies of Four Different Neotropical Ecosystems with Special Reference to their Ephemeroptera Fauna. 120 p. Kassel.

Seather, O. A., 1972, Das Zooplankton der Binnengewasser. I., Teil VI., Chaoboridae, Die Binnengewassser, Band XXVI: 257-280

Sözen, M., Yiğit, S., 1999. Akşehir (Konya) Gölü Bentik Faunası ve Bazı Limnolojik Özellikler, Tr. J. of Zoology 23(3): 829-847, Ankara

Sperber, C., 1948, A Taxonomical Study of the Naididae. Zool. Bidrag, Uppsala Bd 28: 1-296

Sperber, C., 1950, A Guide for the Determination of European Naididae, Zool. Bidrag, Uppsala Bd 29: 45-78

Stobbe, H., 1985. Bestimmungsschüssel für Libellen Deutscher Jugendbund für Naturbeobachtung, 50 p. Hamburg. 
Şahin, Y., 1987. Egridir Gölü Chrinomidae (Diptera) Larvaları ve Yayılışları,Doğa TU Zooloji D. 11,1

Şahin, Y., 1987a, Doğu Anadolu'da Tespit Edilen Yeni Chironomidae (Diptera) Türleri, Doga Tr. J. Of Biology, 11(2): 51-58.

Şahin, Y., 1987b, Burdur, Beyşehir ve Salda Gölleri Chironomidae (Diptera) Larvaları ve Yayılışları, Doğa TU Biyoloji D., 11(2): 59-70

Şahin, Y., 1991, Türkiye Chironomidae Potamofaunas1 (TBAG-869 ve VHAG-347, TBAG-669, TBAG-792 nolu projeler).

Tanatmış, M., 1993. Sakarya Nehir Sistemi Ephemeroptera Limnofaunasının Tespiti ve Yayılışları. Anadolu Üniversitesi Fen Bilimleri Enstitüsü, Doktora Tezi, 136 s, Eskişehir.

Tercedor J. A., 1990. Life Cycle and Ecology of Mayflies From Sierra Nevada (Spain). IV. Bolletin Asoc. Esp. Entom., 23-33.

Timm, T., 1970. On the fauna of estonian Oligochaeta. Pedobiologia, Bd. 10: 52-78

Timm, T., 1999, A Goide to the Estonian Annelida, Issued by the Estonian Naturalist' Society, Tartu, Tallinn, $208 \mathrm{p}$.

Tully, O., T.K. McCarthy ve D.O. Donnell.2004. The Ecology of Corixidae (Hemiptera: Heteroptera) in The Corrib Catchment, Ireland. Hydrobiologia, 210(3):161-169

Ulmer, G., 1961. Die Süsswasserfauna Deutschlands, Trichoptera, 201 p. Berlin.

Wallace, I. D., Wallace, B., Philipson, G. N., 1990. A Key to the Case-Bearing Caddish Larvae of Britain and Ireland. Freshwater Biological Association, 51: $237 \mathrm{p}$.

Wetzel, M.J., Kathman, R.D., Fend, S.V., Coates, K.A. 2000, Taxonomy, Systematics and Ecology of Freshwater Oligochaeta, Workbook Prepared for North American Benthological Society Technical Information Workshop, 48th Annual Meeting, Keystone Resort, CO. 120 p.

Wiggins, G. B. \& Mackay, R. J. 1978. Some relationships between systematics and trophic ecology in Neartic aquatic insects, with special reference to Trichoptera. Ecology 59(6):1211-1220.

Williams, D.D. 2006. The Biology of Temporary Waters. Oxford Biology. 348 s.

Yarar, M., Magnin, G. 1997, Türkiyenin Önemli kuş Alanları. Doğal hayatı koruma derneği, ISBN: 975-96081-6-2, 313s.

Zhadin, V.I. 1952. Mollusks of Fresh and Brackish Waters of the U.S.S.R. Academy of Sciences of the Union of Soviet Socialist Republics, Israel Program for Scientific Translations Ltd., 46: $1-368$. 